\title{
Discussion on the Application of Chinese National Cultural Elements in the Design of Animation Original Painting
}

\author{
Bingxu Ni ${ }^{1, *}$ \\ ${ }^{1}$ Fuzhou University of International Studies and Trade, Fuzhou, Fujian, China \\ "Corresponding author. Email: 2662046667@qq.com
}

\begin{abstract}
Chinese national culture has the genetic role in animation creation and design. It is the cultural root of artistic creation. It is because of its existence in many excellent works that it makes the work more alive. This article takes the current situation of animation creation in China as a starting point, and analyzes the current situation of national culture and examples of successful use of national cultural elements in the original animation, to find the place and connotation of national culture to enhance the creation. From face to point, from shallow to deep, national cultural elements are organically integrated into the design of modern animation original paintings, forming a trinity of inheritance, development, and innovation, and serving for the creation of fine art products with the spirit of the times.
\end{abstract}

\section{Keywords: national culture and elements, animation original painting, design, application innovation}

\section{INTRODUCTION}

With the rapid development of China's society, many foreign animations are also constantly pouring into the Chinese market. The emergence of a large number of animations has a certain impact on the value orientation and aesthetics of Chinese, and it has a great impact on China's traditional animation industry.

In the creation of the animation original painting, it is necessary to inherit and carry forward China's excellent traditional culture, so that it can fully demonstrate its strong vitality. Due to the interference of various factors, it has become a confusion in animation creation in recent years. From macro aspects, it is a problem on the level of cultural aggression, which is related to where Chinese roots are. This problem has already been occupied by the collapse of western culture, so as a young student, it is difficult to find the root of Chinese culture. If there is no cultural confidence, the root of culture would come from nowhere.

Now, to enhance the self-confidence of Chinese people in Chinese animation, it is a must to trace the roots and find the support point of cultural selfconfidence, in order to lay a solid foundation for the development of China's animation industry. From the mirco aspects, it is also an indispensable creative method for enriching works. The five-thousand-year history of civilization is the only country in the world that has no cultural dysfunction. Chinese writings have been passed down for thousands of years. Chinese history can be changed. However, the inheritance of culture has not been cut, and there are a lot of cultural elements in it, which will benefit a lot from any cultural style. Only the national is the international, otherwise there will be no Leonardo, Michelangelo ... Monet, Van Gogh, Picasso, even Disney, Pixar ... of course, including Japanese contemporary animation and so on. However, for unknown reasons, Chinese artists have lost the roots of national culture, resulting in the products that are supposed to bein strong culture, have lagged behind the history and culture and the West that cannot be matched.

Chinese national culture and its elements are not optional in the creation of the animation original painting, but cultural self-confidence supports the spiritual pillar. It is also the only way to become a strong animation country.

\section{DEVELOPMENT STATUS OF ANIMATION IN CHINA}

\section{A. The tree without roots}

In recent years, the overall development of animation in China has been relatively slow. The increasing influx of foreign animations has affected the value orientation and aesthetic consciousness of young people in China to a certain extent, so that the spiritual needs of young people have been subtly changed invisible. Not only that, but more seriously, their works and ideas have become intangible standards rooted in the creation and appreciation of Chinese artists and 
audiences. Once they encounter problems, they will find answers in Western and Japanese animation, making people lose even their ability to judge.

There are many factors that cause this situation, but China works abandoning the national cultural tradition and over-imitation of "imported goods" are important reasons for it, making the creation be the water without source and the tree without roots. "Making the ancients serve the present, and making the foreign serve the Chinese." This is a philosophical idea of "use" proposed by a great man. The subject for whom is used is very clear, that is, today, China. As for how to "use", it is not copying, but absorbing reasonable factors, drawing on successful experience, and making people more plump to form the artistic personality. It is not to let "foreign" and "ancient" take place in today's China, but to serve today's China.

Now Chinese artist creation, Miyazaki Hayao and Michihiko Suwa are their main topics when talking about animation. It is undeniable that they have indeed achieved great success. However, this is by no means a reason for imitation and plagiarism. It is necessary to study why they can be successful, what are the factors of their success, what can be learned from them, and what can be taken as references? The simplest reason is that without the accumulation and elements of Yamato's national culture, there would be no such success for them. Their roots are in Japan. Only when they extend upward on their fertile soil, they grow into towering trees. It is a pity that no one pays attention to these problems. People just want to take them, find a shortcut to cut the way. Unconsciously they lose themselves, and lose the cultural soil on which they live. This is not part of the Western conspiracy. There is no evidence to comment on. However, it can be known that this phenomenon is of no benefit to the development of Chinese culture and art, especially the development of the animation field. No creations can an artist make when he has lost himself. Just like animals in nature, there is no evolutionary function, and the original function is lost. Their results can only be eliminated. the law of natural selection is the same in all things, including Chinese animation art.

Cultural aggression is the essence of all aggression. The wealth can be recreated when being taken away, but when the root of culture is cut off. what else does the country have! This is a big issue worthy of the attention of all artists. It can be said that quite a few groups and individuals have taken the path of "selfabiding martial arts" in the development of China's modern animation industry. There are conditions of substituting "foreign" for "Chinese" and even using "foreign" to extinguish "Chinese". Of course, there are some people who graft and transplant the foreign culture, but unfortunately they have not found the cultural and ecological law (because the most basic of this ecology is cultural soil), and become a alternative laboratory specimens that cannot survive.

The development of Chinese animation lacks the roots of Chinese national culture and fails to reasonably absorb the core of foreign animation art, resulting in unacceptable or even premature death, which has formed a lagging situation in the animation industry today. In recent years, very few artists have followed the laws of artistic creation and made some attempts to change the "foreign" to "Chinese" and work hard on the "root" of national culture, and have made some achievements. Although it can't be compared with the glorious period, the creation of some works still makes people see some hope. It is a pity that there are too few in the mighty anime river, which can only be regarded as a few waves in the animation river.

\section{B. Personnel structure}

People in China's animation industry generally have low cultural and artistic qualities because they only view it as technology, and do not sublime to the ideological and artistic level. It's just a one-sided pursuit of immediate interests, following the trend and following the trend at the expense of everything, and there is no basic cultural accumulation. Therefore, in the creation of animation, the selected themes are relatively narrow, and the refined themes are also superficial, plus the overall level of production is not satisfactory, and the product is not competitive. The reason for China's backwardness is simply the loss of cultural self-confidence. The cultural heritage of China for thousands of years, the essence left behind is like the rivers and the sea. If summed up in classics, The Classic of Mountains and Seas, Zhou Yi, Tao Teh King ... Hundred Schools of Thought ... The Songs of Chu, poetry in the Han Dynasty, poetry of the Tang Dynasty, Song Poems, Yuan opera ... poetic dramas and novels in the Ming and Qing Dynasties conveyed not only a certain cultural style, but also a deep spirit. These are Chinese most precious cultural self-confidence supports. It is a pity that the creators have not been able to cultivate in such fertile soil, but have spared no effort to plant forest trees in an exotic bonsai world. The basic reason of this phenomenon is the lack of education. These employees have no foundation for such education from growth to entry, and have formed a status quo with generally low cultural and artistic qualities. This problem is not the problem of a person, but a problem that society needs to address and solve.

\section{Misunderstanding of creation}

There is a simple misunderstanding in China, that is, animation is a patent for children. From creation to production, the works are designed to cater to the needs of younger children. This has led to the narrow theme of animation creation in China, and the lack of highlevel ideas. Good animation works can be suitable for 
both young and old, and enjoy both elegance and vulgarity. For children, not just children, the classic works such as "Son Gokū Havoc in Heaven" have fascinated many adults. Many of these examples are no longer listed one by one. Animation works must go out of this misunderstanding before they can usher in the spring of creation.

\section{THE CORE VALUE OF ANIMATION ORIGINAL PAINTING CREATION AND DESIGN}

\section{A. Creation of animation original painting}

From a single perspective on the creation of animation original painting, the design of Chinese original paintings can reasonably apply the elements of Chinese national culture to the creation of original paintings, infiltrate the fragrance of Chinese national culture, and achieve the purpose of "ancient for the present", which is equal to half the success. In the five thousand years of civilization history in China, the accumulation of culture is beyond imagination, and it can be said to be everywhere. Drawing inspiration and nutrition from such a treasure trove is rare in the world, and it is truly unique for Chinese creators. If the creators combine the creative ideas that are in line with the times, change the inherent immutable state, and open the brain hole to expand the space of association and imagination, this would be equivalent to the other half of the success. The addition of two semicircles is a complete circle.

When the original painters in foreign countries choose materials, they often like to intercept the elements on the surface. Seriously speaking, this can only be regarded as a symbolic creation. Some people try to exaggerate this effect. This is different from what the creators emphasized to draw nutrients from the deep accumulation of national culture. It can't get the essence. From concept to concept, it is the transmission and expression of the surface. This not only misinterprets the original cultural core, but also breaks down the stability and rich connotation of traditional cultural elements. This is very similar to European-style Chinese food or American-style Chinese food. It can't even make color flavors, let alone "cooking" state and artistic soul.

Animation creation deviates from the real situation and life. It is simple and rude to directly use the socalled national elements to create conjectures. It must be said that it is a castration of national culture. If local artists can rise up, take on the role of renaissance, clean the source, reasonably "mine", and effectively use Chinese extensive and profound cultural resources, the Chinese national cultural elements will definitely shine in the animation field.

\section{B. The status of original painting design in animation}

The design of the original painting is the core link of the animation creation, and it is also the basis for the action design of the characters in the animation. At the same time, when writing animation programs, it must refer to the original script. The original painting is a basic design basis for animation, and has a fundamental meaning for the character's movement, shape and speed. The positive effect of a good original painting on the development of the animation industry is selfevident. The position of the original painting in the animation production cannot be replaced. There is no animation without the original painting. It is the focus of animation in every link and the decisive factor for animation success.

If the original figure is unsuccessful, there can be no success in the animation work.

Therefore, the original painter is the core character of the entire animation work. The state of his performance determines the works he presents. What is throughout the entire animation design is the original painter's performance ability and technical level in the creative process. Whether it is possible to smoothly tell the story and complete the characterization of the character through the character's behavior and body language, the display of the character's inner activity is the most important link, and this link depends on the animation's mastery and grasp of the original character.

Many excellent animation works can leave a very deep impression on people's minds. More of them are the original painting masters' unremitting pursuit of artistic standards when portraying characters. Through the expressive power of the original painting, the characters created by them have been given strong vitality. To grasp this hard core in animation production and creation and production, it will leave the audience with an unforgettable animated character image, giving the audience a strong artistic appeal. The continuous development of the animation industry not only brings opportunities for animation practitioners, but also provides a broader stage for original painting creators.

Therefore, it is a must to grasp the two ends, of which one is the creation and selection of the original source animation, and the second is the re-creation and production of the production link. On the basis of combining the two organically and exerting their respective advantages, they work together to tell good animation stories, create more distinctive animated characters, and leave a lively artistic image. This is what animation should be. 


\section{APPLICATION TYPES OF CHINESE NATIONAL CULTURE IN THE DESIGN OF ANIMATION ORIGINAL PAINTING}

\section{A. Chinese stories}

Chinese culture has a history of 5,000 years of historical development and accumulation. In the long river of history, many valuable stories and characters have been born, which have been handed down from generation to generation. It is a treasure trove of animation creation.

1) Composition of Chinese stories: The first is the works in the literary treasure trove, such as the masterpieces of various periods, such as "The Classic of Mountains and Seas" and many historical masterpieces, etc. Of course, there are quite a few of them from folk, and finally processed by the writers to form classic literary works, such as "Journey to the West", "Strange Stories from a Chinese Studio" and so on.

The second is from pure folk including textual and verbal narration, such as "Chinese Classics \& Culture" and "In Search of the Supernatural", etc., which are collected and sorted out.

The third is the stories formed from real people in life, including heroes, models, various celebrities and even ordinary people. Such stories are often dominated by characters, such as Yue Fei, Wen Tianxiang, Qi Jiguang, etc., as well as cultural celebrities Qu Yuan, Li Bai, Su Dongpo, etc. There are also some historical events, such as the Sino-Japanese War of 1894-1895, the July 7 th Incident and so on.

Many of the materials in contemporary works are directly taken from real life, and have the characteristics of freshness and sense of time. For example, a large number of small animations depicting Wuhan's fight against the "novel coronavirus" epidemic, which has been circulated on the Internet, not only received everyone's approval, but also played a very encouraging role in defeating the epidemic. This kind of Chinese storytelling is experienced by everyone, and it is easy to resonate.

2) The public foundation of the Chinese stories: Most of the Chinese stories can be widely circulated because they embody China's traditional virtue and aesthetic orientation, and play a subtle educational role in life. In the animation creation of contemporary China, many works are re-created with Chinese stories, which has achieved great success and has had a greater impact on society.

"Monkey King: HERO IS BACK", released in 2015, has been loved by audiences from all levels. The film mainly incorporates the stories in China's famous literary book "Journey to the West". Such Chinese stories have laid a solid audience base for the film. Because "Journey to the West" is a well-known Chinese story, it is a cultural mark of the growth of generations.

Integrating Chinese stories into the creation of animation can enable the creation and design of animation to have a solid mass foundation. Revolving around the development of Chinese stories, it is easy to maintain the integrity of the overall structure of the animation and a reasonable development context when imaginatively describing the animated characters. The use of Chinese stories as scripts in the animation provides a favorable background for animation creation, and the artists can follow the rules when describing the details in the animation.

3) The creative space of Chinese stories: The creation of Chinese stories has a certain theme and is subject to certain restrictions. Sun Wukong cannot be written as a panda in Kung Fu Panda. However, under the premise of wide recognition, as long as it does not exceed the recognition range of the audience, any processing and creation can be successful. It can be said that the space is huge.

In the process of creating the animation original painting, it is necessary to learn to tell a good Chinese story, correct the relationship between inheritance and innovation, constantly improve the richness of the animation content and the novelty of the technique, form the personality created by the artist, and enhance the public's awareness of Chinese animation to promote the development of China's animation industry.

\section{B. Utilization of national cultural elements}

1) Application of facial makeup art: The integration of Chinese ethnic elements in the development of animation is not only reflected in the content of the story, but also the use of character images. This use can effectively enhance the image of the characters in the animation and enhance people's recognition of the work. When designing animated characters, the flexible use of paper-cutting, facial makeup and other arts can enhance the recognition of the character's image.

The art of facial makeup is a reflection of the essence of traditional culture. Applying facial makeup to the shape of the animated original painting characters can enhance the richness of the animated characters and narrow the relationship between the audience. For example, in the animation "Nezha Conquers the Dragon King", most of the characters in the animation use facial makeup elements, which greatly enhances the attractiveness of the work. The villain "Hundun" in the animation used the elements of facial makeup when designing the shape of the character, making the image of the villain full and leaving an unforgettable impression on the audience. 
2) Reasonable use of martial arts: When designing the movements of animated characters, the development of movements is an important part of the whole plot. Designing reasonable movements improves the enjoyment of animations and brings a greater visual impact to the audience.

In China's animation original painting design, there are many works that incorporate the action of Chinese martial arts, making the fight in the animation much clearer and smoother, and greatly improving the appreciation of the work. In "Monkey King: HERO IS BACK", the development of the animation plot has more fighting scenes, and most of the movements in the design of these scenes are from Chinese martial arts. Martial arts is an integral part of Chinese traditional culture. When designing the movements of the characters in the works, it has a unique advantage. Applying it reasonably to the design of the character's movements will effectively increase the animation visibility.

3) The use of ancient architecture in designing scenes: In the design of animation, complete animation needs to be supported by scenes, and scene design has a pivotal position and role in animation creation. The scene design of animation is not only set against the background of the animation, but also creates a good visual situation for the audience, effectively highlights the plot of the characters in the animation. It is of great significance to deepen the theme of the work and enhance the taste of the work.

At present, China's animation creators have incorporated a large number of ancient architectural elements into the design of the scene. The use of ancient buildings in China's animation has made it possible to display its unique oriental charm. For example, in the animation "Little Door Gods", there are more such scenes, which makes the town have the mysterious color of the east, and it has been unanimously praised. Also at the end of the movie "Monkey King: HERO IS BACK", it shows the ancient "Xuankong Temple" building in China. The overall drawing has a relatively large degree of recognition, which gives the audience a sense of intimacy and makes the visual sense of the animation achieve the bursting effect.

4) Integration of folk customs and ancient landscapes: As in the film above, in the "beating Monster Nian" scene at the end, the unique "Spring Festival" elements of China are incorporated to cater to the psychological needs of the Chinese audience and to enhance the viewing effect. Similarly, in the animation "Wind Spell", the overall scene design is based on the landscape of China with ancient styles, which is close to the aesthetic needs of Chinese audiences, and makes the animation more realistic and time-sensitive.

\section{THE SPECIFIC APPLICATION OF CHINESE NATIONAL CULTURAL ELEMENTS IN THE DESIGN OF ANIMATION ORIGINAL PAINTING IN CHINA AND FOREIGN COUNTRIES}

\section{A. Chinese national cultural elements in Chinese animation}

Chinese animation creation has a history of more than 80 years. Since the beginning of the industry, it has been closely integrated with national cultural elements, and a large number of outstanding works have been born in China and foreign countries. Many animation creations use various national cultural elements such as shadow puppets, paper-cuts, New Year pictures, and calligraphy, highlighting China's unique animation image and expression techniques. In the development of the animation industry, without incorporating the outstanding traditional cultural elements of the nation, it is difficult to have success of the predecessors. Today's animation industry needs to integrate originality with a rich national culture. The national is the international, so that Chinese animation film creation has an influence.

There were two climaxes of animation art creation in the 1960s and 1980s. During these periods, the animation works have a strong ideological and artistic nature, and have the characteristics of China's national culture. These works have entered the market one after another and won many international awards. With the development of Chinese animation, they have also been gradually recognized by the world. The reason why Chinese animation has been able to achieve such great success in these two periods is because it has absorbed the essence of traditional Chinese culture.

In the cartoon "Havoc in Heaven" produced in the $1960 \mathrm{~s}$, whether in the modeling of characters or in the creation of music, the elements of Chinese Peking Opera are merged and processed, and the creative material for the animation comes from Chinese classic literature. Not only that, it also incorporates a variety of rich artistic elements such as Chinese door paintings, temple arts and Dunhuang murals into the film, so that the animation protagonist Sun Wukong's image penetrates into the hearts of the people and shows a distinctive national style.

Of course, it cannot exclude the reason for reasonably absorbing the success of foreign animation creation, making it play a role in the promotion of Chinese works. For example, "Princess Iron Fan" created by the Wan Brothers is the first long animation in China. In this animation, the design of "Sun Wukong" incorporates the action characteristics of 
"Mickey Mouse". Due to the proper application, it also makes the work more colorful.

\section{B. Chinese national elements in the creation of foreign animation original paintings}

With the continuous development of China's comprehensive strength, Chinese traditional culture is also increasingly loved by people around the world. When the West is exploring the way out of modernization, it has set its sights on China.

The American Disney Company once changed Chinese traditional folk story "Mulan Joins the Army" into a new version of the animated film "Mulan". The cartoon "Kung Fu Panda" created by DreamWorks in 2008 is a typical combination of Chinese and Western culture. Westerners learn nutrition from China's huge treasure trove of traditional culture and realize the successful combination of the two cultures, which is a good reminder for Chinese people.

In the animation production of "Mulan", more of the Chinese-inspired images are used. In the creation, some techniques of Chinese painting are borrowed, and the virtual and the real, and traditional Chinese realistic painting and Chinese ink painting are combined. Combining the virtual painting method with the defocusing of the lens, it effectively avoids the contradiction that the drawing of ink animation is not easy to integrate with the three-dimensional animation realism, and renders the artistic conception expressed by animation, so as to coordinate and balance between realism and freehand. In the background architecture and character modeling of "Mulan", the rounded brushstrokes of Chinese painting are used in many details to create shapes, such as smoke line drawing, etc., which makes the whole film full of strong Chinese style.

When animation creation is combined with profound Chinese cultural connotation, the essential meaning of animation can be displayed to the maximum extent, and its development in the market has higher value.

\section{CONCLUSION}

Telling Chinese stories well and elevating the elements of Chinese national culture to the necessary height during the animation design process are not only the development needs of the times, but also the development needs of animation art itself. Focusing on the organic integration of Chinese national cultural elements in the design and creation of animation is an inevitable historical development. Continuously improving the ability of China's animation creation to use national cultural elements is an important foundation for the sustainable development of China's animation industry. The above goals are for Chinese animation products to have a certain visual impact and competitiveness.

\section{References}

[1] Cui Jun, Pu Pengju, Pang Like, The Application of Shaanxi Traditional Cultural Elements in the Original Painting Design [J]. West Leather, 2019, 41(15): 70. (in Chinese)

[2] Jiang Zhenjie, Yang Yongjuan, Jin Yi, Discussion on the Importance of Native Elements in the Teaching of Origina Painting [J]. Occupation, 2016 (02): 158-159. (in Chinese)

[3] Wang Huiying, Jin Wei, A Brief Talk on the Use of Elements in the Design of Game Characters' Original Paintings [J]. SP, 2019 (03): 280. (in Chinese)

[4] Wang Lin, The Application of Folk Culture in the Northwest of Hunan in the Design of the Game Original Painting [J]. Industrial \& Science Tribune, 2019, 18(04): 196-197. (in Chinese)

[5] Liu Yixuan, Analysis on the Style and Thinking of Chinese and Foreign Original Painting Design [J]. Drama Home, 2017 (13): 141. (in Chinese)

[6] Qiao Zhaolun; Li Yang. Analysis of the application of Chinese ethnic elements in the design of the original animation. Family of the Drama. 2019 (07). (in Chinese)

[7] Pang Like; Pu Pengju. The exploration of original painting design with traditional culture as the theme under the new media background. Art Science \& Technology. 2017 (11). (in Chinese)

[8] Wen Yuekun. Research on the design of the original painting of ethnic style games. Satellite TV \& IP Multimedia. 2020 (02). (in Chinese)

[9] Zhao Xingbiao. An analysis of the importance of Chinese traditional elements in the design of original paintings. Art Education Research. 2018 (15). (in Chinese)

[10] Yan Bo. On the design of original paintings in cartoon production. Popular art. 2017 (02). (in Chinese) 